\title{
Electromagnetic Tissue Fusion Using Superparamagnetic Iron Oxide Nanoparticles: First Experience with Rabbit Aorta
} \author{
Michael Münker ${ }^{\mathrm{e}}$, Istvan Vajtai ${ }^{\mathrm{f}}$, Martin Frenz ${ }^{\mathrm{d}}$, Heinrich Hofmann ${ }^{\mathrm{b}}$ and Michael Reinert*,a \\ ${ }^{a}$ Department of Neurosurgery, Inselspital Bern, University of Bern, Switzerland \\ ${ }^{b}$ Laboratory of Powder Technology, École Polytechnique Fédérale de Lausanne, Switzerland \\ ${ }^{c}$ Microsystems Laboratory 4, École Polytechnique Fédérale de Lausanne, Switzerland \\ ${ }^{d}$ Institute of Applied Physics, University of Bern, Switzerland \\ ${ }^{e}$ Department of Clinical Physics, University Medical Center, Utrecht, The Netherlands \\ ${ }^{f}$ Institute of Pathology, University of Bern, Switzerland
}

Amadé Bregy ${ }^{\mathrm{a}}$, Andreas Kohler ${ }^{\mathrm{a}}$, Benedikt Steitz ${ }^{\mathrm{b}, \mathrm{c}}$, Alke Petri-Fink ${ }^{\mathrm{b}}$, Serge Bogni ${ }^{\mathrm{d}}$, Alex Alfieri ${ }^{\mathrm{a}}$,

\begin{abstract}
Large open surgical approaches are being extensively replaced by endoscopic and robotic techniques. Yet, these developments have not been paralleled by the necessary improvements in tissue adaptation, fusion or fixation. In order to advance the surgical area to a higher and improved level, adequate tissue fusion methods need to be designed. We therefore developed a sutureless electromagnetic tissue soldering technique, using superparamagnetic iron oxide nanoparticles (SPIONs). A magnetic field in combination with SPIONs as energy transmitters for absorption was used to fuse rabbit aortic tissue in vitro. Temperature profiles and rupture forces of the fused vascular tissue were measured and histological analyses were performed. The rupture force of the fused rabbit aortas was $3078 \pm 852 \mathrm{mN}$. The experiments revealed the feasibility of tissue fusion by electromagnetic heating of SPIONs, which proved to be a novel promising tissue soldering technique.
\end{abstract}

\section{INTRODUCTION}

Development of micro-optics has fostered a constant improvement of visualization in minimally invasive and endoscopic techniques, thereby reducing tissue injury during surgical procedures [1]. These developments have however not always been paralleled by technical effectiveness of sutureless tissue fusion. Research on the latter topic over the last three decades, particularly in laser welding and soldering, has shown effectiveness only on a small scale, although the introduction of an albumin solder doped with indocyanine green (ICG) to selectively absorb laser light has significantly improved tensile strengths [2-5]. Previous tissue soldering experiments revealed that good anastomoses with high tensile strength and minimal tissue damage are obtained if the applied albumin solder is homogeneously heated to a temperature of about $80^{\circ} \mathrm{C}[4,6]$. The main problems laserassisted tissue fusion techniques still have to deal with, are irregularities of heat deposition in the solder caused by inhomogeneities in the solder absorption leading to spatial variations in the optical penetration of the laser radiation in the tissue.

To overcome these optical problems, we developed an electromagnetically based tissue fusion system using superparamagnetic iron oxide nanoparticles (SPIONs). Energy absorption in SPIONs is due to Néel relaxation, which is caused by reorientation of the magnetic dipole moments

*Address correspondence to this author at the Department of Neurosurgery, Inselspital Bern, University of Bern, 3010 Bern, Switzerland; Tel: + 4131632 2486; Fax: + 4131382 2414;

E-mail: michael.reinert@ neurochirurgie-bern.ch inside the (fixed) magnetic core (particle) against an energy barrier. The strength of the Néel relaxation mechanism depends on the size and saturation magnetization of the particles, the frequency and magnetic strength of the applied electromagnetic field and on the temperature. Maximum heating has been shown for particle sizes ranging between 10 and 20 $\mathrm{nm}$ with field frequencies ranging between 1 and $27 \mathrm{MHz}$ [7].

In this study we investigated the feasibility to solder vascular tissue by electromagnetic heating using SPIONs as energy transmitters. The results were evaluated with regard to their heating ability, the tensile strength of the fused tissue and the thermally induced tissue damage.

\section{MATERIALS AND METHODS}

\section{Radiofrequency System}

A frequency generator (Power Controller 32/1800, Ceia, Italy) operating at a constant frequency of $1.8 \mathrm{MHz}$ and a constant flux of $40 \mathrm{mT}$ was used in all our experiments. A thin water-cooled copper coil built up the high frequency electromagnetic field. The single turn coil had an outer diameter of $5.5 \mathrm{~mm}$, whereas the tube itself had a diameter of $1.5 \mathrm{~mm}$. The output power of the generator was controlled by pulse width modulation (PWM). Power levels of $10 \%$, $20 \%, 30 \%, 50 \%$ and $90 \%$ (PWM) were used. This means that $50 \%$ PWM leads to an alternate switching on and off of the generator, resulting in a duty cycle of 0.5 .

The temperature at the soldering spot was measured by a fluoroptical contact temperature sensor (FOT Lab-Kit, Luxtron, CA, USA), which recorded the temperature at a fre- 


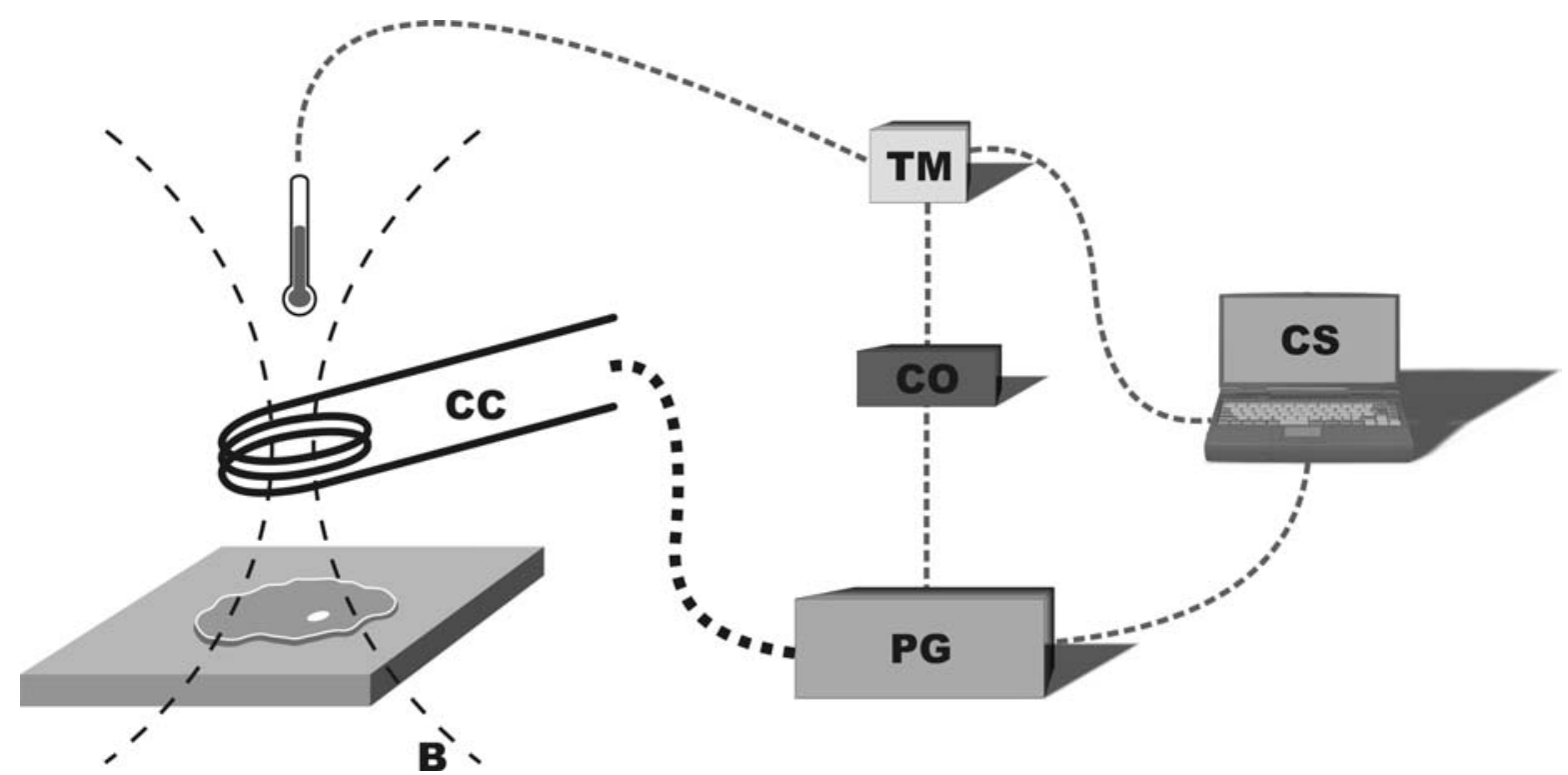

Fig. (1). Experimental setup. The high frequency power generator (PG) that is connected to a thin water-cooled copper coil (CC) induces an electromagnetic field (B). A fluoroptical temperature measurement system (TM) in conjunction with a power controller (CO) regulates the output power of the generator (feedback mechanism). The computer (CS) records the temperature and power setting data.

quency of $4 \mathrm{~Hz}$. A negative feedback control between the temperature measurement system and the generator control unit enabled a fast and precise steering of the temperature (Fig. 1).

As radiofrequency energy receiver, a water-based suspension of $\mathrm{Fe}_{2} \mathrm{O}_{3}$ nanoparticles (SPIONs) with a particle diameter of $15 \mathrm{~nm}$ was used.

\section{SPION-Albumin Solder}

The solder consisted of $20 \%$ (w/w) of bovine serum albumin (BSA, Cohn Factor V, Sigma-Aldrich, Switzerland) dissolved in pure sterile water. Dissolving was accomplished in a water bath at $37^{\circ} \mathrm{C}$ and accelerated by a magnetic stirrer. SPIONs concentartions of $5 \%, 10 \%$ and $20 \%(\mathrm{w} / \mathrm{w})$ were used in the experiments.

\section{Determination of Optimal Heating Parameters}

The maximum temperature reached on the tissue surface was determined using a constant solder volume of $30 \mu \mathrm{l}$ of BSA and different SPIONs concentrations of 5\%, $10 \%$ and $20 \%(\mathrm{w} / \mathrm{w})$. The power was set constant at $90 \%$ (controlled through PWM) and the distance from the coil to the solder was kept constant at $1.2 \mathrm{~mm}$. These experiments were performed with the temperature feedback system turned off.

\section{Soldering Experiments}

Rabbit abdominal aortic arteries were used for the in $v i$ tro soldering experiments. The aortic arteries were extracted and immediately frozen at $-20^{\circ} \mathrm{C}$. Prior to use, they were thawed to room temperature.

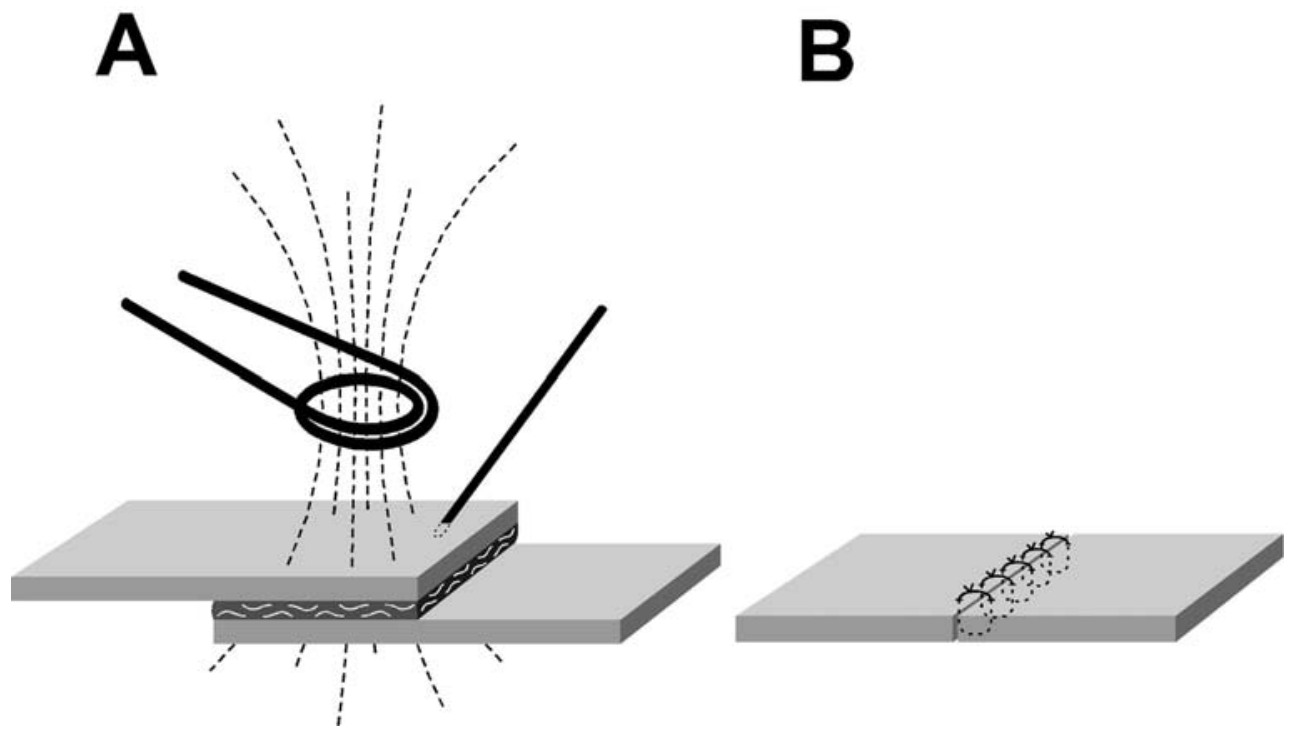

Fig. (2). Schematic drawing of the tissue fusion procedure and microsuturing technique. In (A) two pieces of tissue are fused with the intermediate of SPION - Albumin solder using the electromagnetic field and temperature feedback. In (B) the conventional microsuturing technique is shown (Prolene 8-0). 


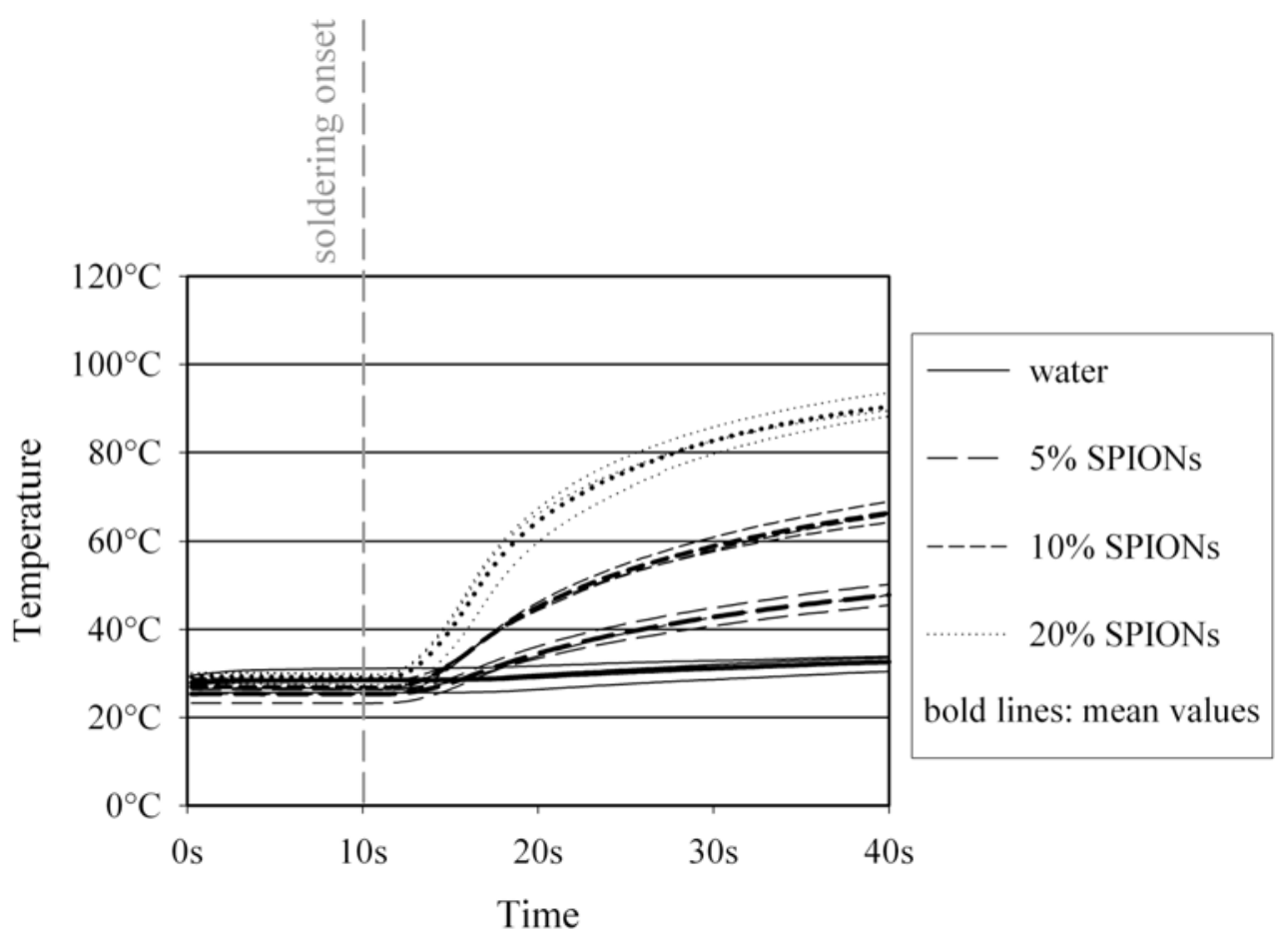

Fig. (3). Temperature profile showing the heating curve of different concentrated SPION-solders. Power output setting of the generator was maintained at $90 \%$ (PWM).

For experimentation, standardized pieces of $15 \times 10 \mathrm{~mm}$ were cut. The two adventitial surfaces were soldered together with an overlapping area of $1 \mathrm{~cm}^{2}$. The tissue was placed into a custom-made tissue holder, enabling a constant distance between the tissue and the induction coil of $3 \mathrm{~mm}$. 30 $\mu \mathrm{l}$ of BSA-SPION-solder was administered between the two tissue samples.

After reaching a temperature threshold of $75^{\circ} \mathrm{C}$, the temperature was regulated by the feedback system to $80 \pm 5^{\circ} \mathrm{C}$ for a heating time of $60 \mathrm{~s}$.

The strength of the soldered tissue connection was quantified by tensile strength measurements, which recorded the maximum force in $\mathrm{mN}$ until rupture, thereby, facilitating the assessment of the vertical shearing stress. A second set of tissue samples was used for histology to determine the extent of thermally induced tissue damage.

\section{Conventional Suturing}

For comparison, we sutured five pairs of tissue samples, identical to those used for the soldering experiments. A (8-0) Prolene thread (Ethicon J\&J, Spreitenbach, Switzerland) was used to accomplish interrupted suture, seven stitches were performed along the tissue edge of $1 \mathrm{~cm}$ (Fig. 2b). Thereafter, rupture forces of the samples were measured.

\section{Histology}

In order to visualize heat-induced supravital alterations in SPIONs soldered aortic slices, microscopic examination was performed. Tissue samples were fixated in 5\% buffered aqueous formaldehyde solution and routinely processed with paraffin. Microscopic slides of $3 \mu \mathrm{m}$ thickness were generated from paraffin blocks and stained with hematoxylin and eosin (HE). As control, identically processed non-heated tissue was used.

\section{RESULTS}

\section{Determination of Optimal Heating Parameters}

A total of 12 temperature profiles were recorded and analyzed for heating with differently concentrated SPION solutions. Increasing the SPION concentration from 5\%, $10 \%$ to $20 \%$ resulted in a linear increase of the solder temperature reached after $30 \mathrm{~s}$ from $56^{\circ} \mathrm{C}$ to $77^{\circ} \mathrm{C}$ and $98^{\circ} \mathrm{C}$, respectively (Fig. 3). Higher SPION concentrations in the albumin solder were tested but they resulted in an inhomogeneous solder solution and were therefore discarded.

As shown it Fig. (3), only the 20\% (w/w) SPION concentration resulted in an absolute temperature increase higher than $80^{\circ} \mathrm{C}$. Thus only the $20 \%$ (w/w) SPION concentration was used for the tissue soldering experiments. Fig. (4) shows temperature profiles recorded during the soldering process with the activated temperature feedback system. The adjusted temperature of $80^{\circ} \mathrm{C}$ was reached $30 \mathrm{~s}$ after launching the frequency generator at $90 \%(\mathrm{PWM})$ and then kept constant for $60 \mathrm{~s}$.

\section{In vitro Soldering Experiments and Suture Tensile Strength}

The rupture force of the soldered tissue samples using the SPIONs was $3078 \pm 852 \mathrm{mN}$ (Fig. 5). Rupture force of the conventionally sutured tissue samples $(n=5)$ was $2580 \pm 950$ $\mathrm{mN}$.

\section{Histology}

Following electromagnetic heating mediated by SPIONs, aortic slices displayed clearly localized supravital alterations of cellular and cytoarchitectonic details, in particular widespread loss of nuclear staining (individual cell necrosis) as well as condensation of interstitial matrix components. No 


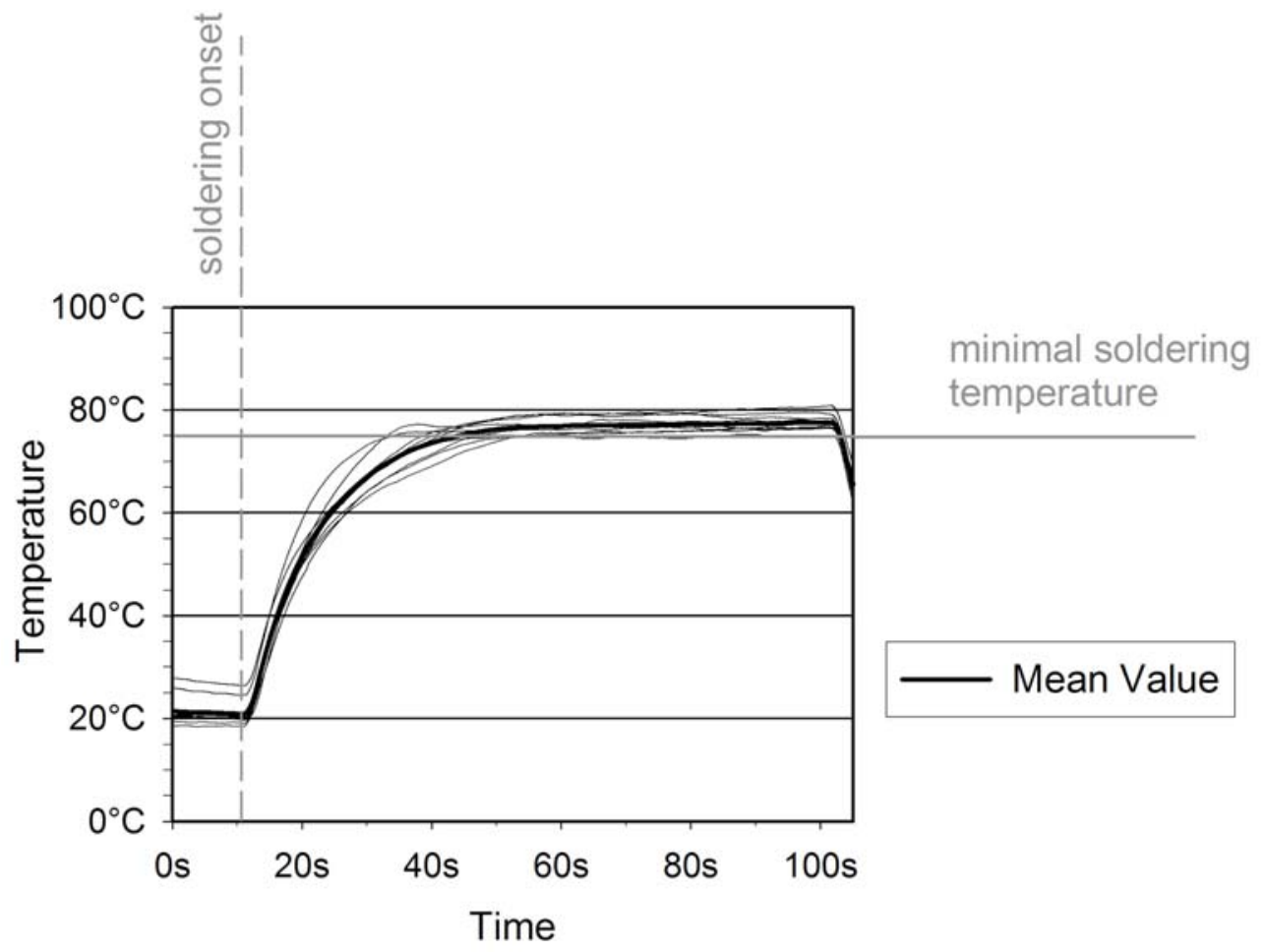

Fig. (4). Temperature profiles of SPIONs $(20 \%$ (w/w)) during the tissue soldering procedure ( $\mathrm{n}=10)$. After 30 s of electromagnetic irradiation, the temperature reached $80^{\circ} \mathrm{C}$, which was kept constant over a period of $60 \mathrm{~s}$.

comparable changes were evident in sham-treated controls (Fig. 6).

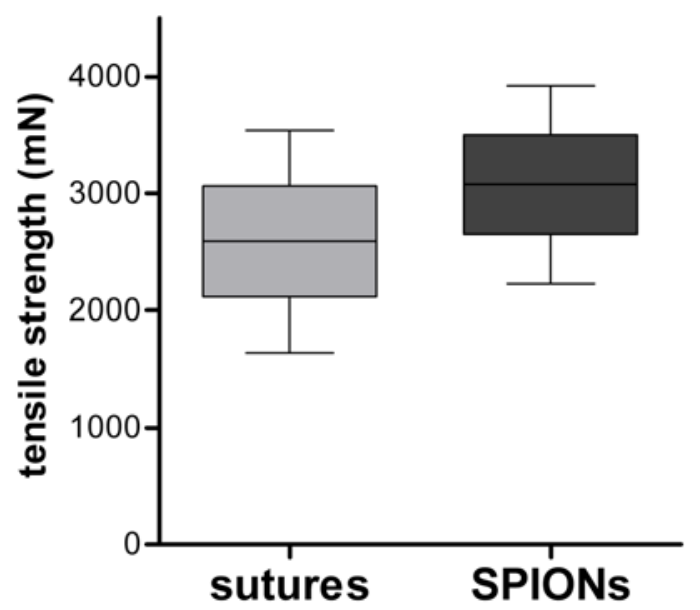

Fig. (5). Box-and-whisker diagram shows rupture force obtained after conventionally with thread sutured rabbit aortas $(2590 \pm 950$ $\mathrm{mN}$ ) and after SPION soldered aortas $(3078 \pm 852 \mathrm{mN}$ (mean \pm $\mathrm{SD})$ ).

\section{DISCUSSION}

Surgical disciplines face an inclination towards minimally invasive approaches by using endoscopic or keyhole techniques. The current optical developments have permitted this miniaturization process to succeed in almost any surgical discipline. As a result, the open surgical approaches have been successively replaced. Meanwhile, the techniques to fuse tissue, a prerequisite also in minimally invasive surgery, have not advanced in parallel. The degree of freedom for using a suture or a microsuture however exceeds the optimal range of motion for endoscopic or keyhole approaches. Therefore, new tissue adaptation techniques are necessary. Micromechanical devices have improved to some extent the miniaturization process for tissue fusion [8]. For most endoscopic techniques, these devices are however still too intensive and dissatisfying. Tissue gluing on a fibrin basis has achieved favor of applicability as sealants. These fibrin based tissue sealants have an insufficient tissue adherence in terms of shearing strength and bursting pressure and experience a resorption after a few days endangering any tissue adaptation [9]. Anorganic based tissue glues demonstrate a much stronger and immediate tissue strength, but the problem of specific tissue toxicity has not been resolved, although the newer generation of butyl-cyanoacrylate has been reported to be less problematic [10]. Laser tissue welding and soldering using a dye such as indocyanine green (ICG) as energy absorber have been studied broadly in the last decades [4], however, a routine clinical application could not yet been established. The main reason for the incapacity to produce reliable reproducible results for laser tissue soldering is the inhomogeneity of the laser light absorption, related to an irregular laser light tissue penetration and to the problem of the ICG-dye runaway during the soldering process [11]. An electromagnetic tissue soldering has the advantage to be free of practically any energy attenuation as passing the tissue. All energy is deposited in the SPIONs leading to homogeneous temperature increase. For a reliable and easy handling application the SPIONs can be embedded and concentrated into a polymer structure. The energy absorption can thereby be realized at the spot of interest, a process not possible for an optically based system. Furthermore, particle gradients can be achieved leading to an optimal energy deposition. 

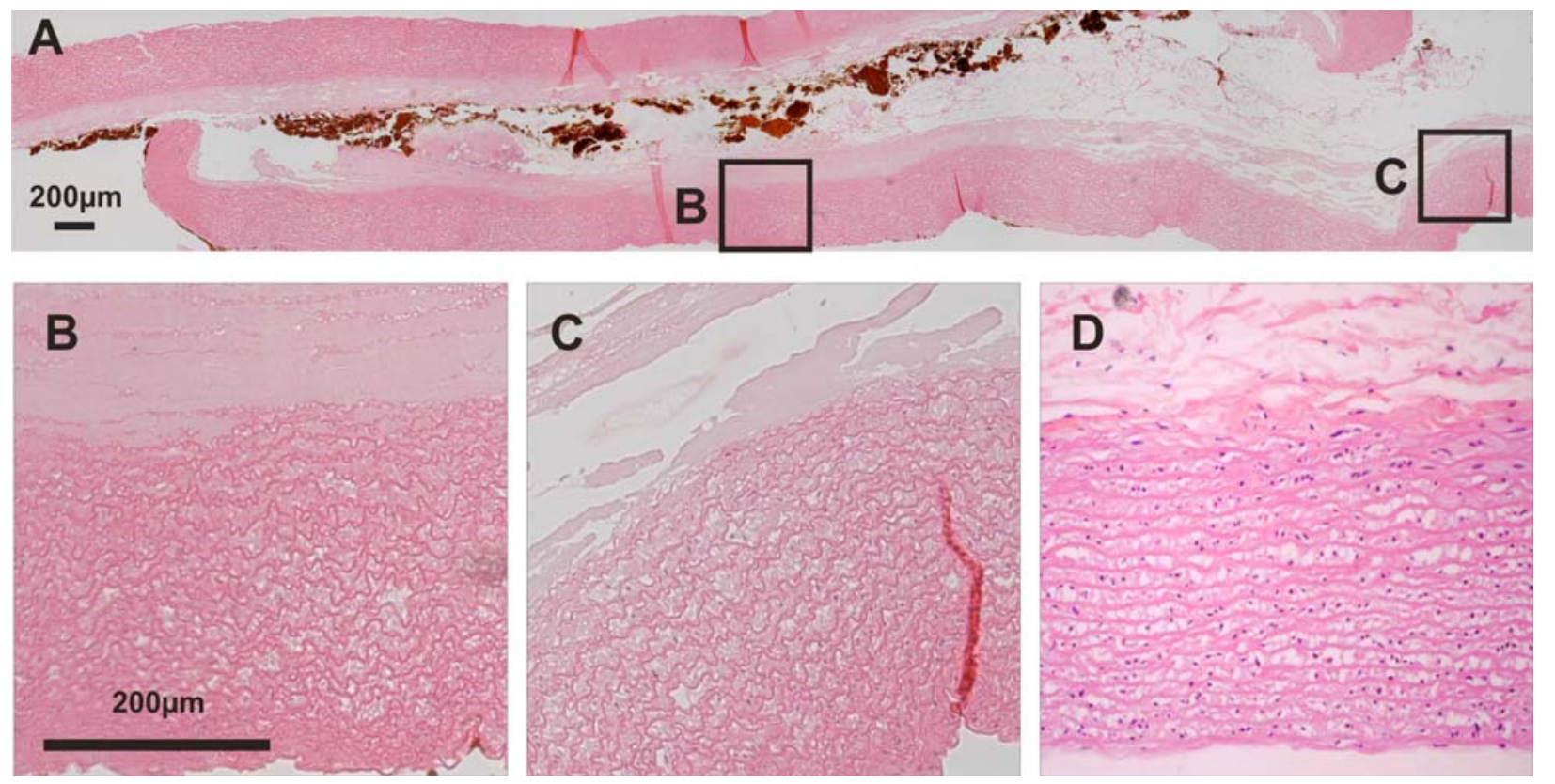

Fig. (6). Microphotographs to illustrate histological aspects of SPIONs soldered and sham-treated aortic walls. (A) Overview of electromagnetically SPIONs soldered slices of rabbit aorta shows experimental anatomic situation involving juxtaposed adventitial layers. (B) Detail of one of a pair longitudinally sectioned aorta taken from the spot of maximal soldering. Supravital loss of nuclear staining of most intramural connective tissue cells is evident. (C) Detail of aortic segment localized outside the maximal soldering area. In contradistinction from (B), a fair number of preserved basophilic (viable) nuclei are appreciated. (D) Sham treated rabbit aorta sections showing innocuous cytoarchitecture and nuclear morphology.

All microphotographs (B, C, and $\mathbf{D}$ same magnification) have been taken from HE-stained slides. Original magnifications are indicated by the bars.

\section{Thermal Soldering Effect}

The factors leading to thermal tissue fusion are not entirely understood. Constantinescu et al. demonstrated that below $80{ }^{\circ} \mathrm{C}$, considered as the temperature suitable for thermal induced tissue fusion, no covalent bonding changes are to be expected [2]. Denaturation of proteins occurs from temperatures above $52^{\circ} \mathrm{C}$ followed by destruction of cellular lipid bilayer and liberation of intracellular proteins and enzymes at temperatures above $80^{\circ} \mathrm{C}$ [12-17]. The best tissue soldering outcomes and minimal heating injury have been obtained by adding a protein such as BSA. This denaturation process, also commonly stated as non-covalent change in protein structure, has not been more closely defined. For clinical application, a homogenous heat deposition at the tissue fusion area is essential. Exactly this prerequisite was obtained using the SPIONs as demonstrated in the histological assessment.

\section{SPION Heating Specifications}

The specific absorption rate (SAR) quantifies the rate of energy deposition in tissue, which is a measure of the amount of energy converted by the magnetic particles from the magnetic field into heat per unit time and mass. Usually, SAR is described by power losses due to Brownian and Néel relaxation mechanisms. For a typical heating application, the diameter of the particles has to be maintained between 10 and $20 \mathrm{~nm}$ and the frequency between 1 and $27 \mathrm{MHz}$ [7]. The specific absorption rate (SAR) was experimentally determined by the initial slope of the heating experiments [18, 19]. Although the maximum temperature recorded after 30 seconds of heating increased linearly with increasing SPION concentration, the measured SAR values decreased from 98 (5\% SPIONs (w/w)) to $95(10 \%$ SPIONs (w/w)) and $83 \mathrm{~W} / \mathrm{g}$ $(20 \%$ SPIONs $(\mathrm{w} / \mathrm{w}))$. This might be explained by magnetic dipole-dipole interactions resulting in increased numbers of magnetically blocked particles at higher SPION concentrations and higher packing density, respectively.

\section{In vitro Soldering}

Electromagnetically SPION soldered tissue showed local stronger tissue destruction when compared to tissue globally heated to $80^{\circ} \mathrm{C}$ and to non-heated tissue samples. We hypothesized that the local temperatures in the SPIONs soldered tissue samples may have been higher than $80 \pm 5^{\circ} \mathrm{C}$ in close proximity of the SPIONs.

The good tensile strength of SPIONs soldered tissue with only circumscribed and limited tissue alteration led us to conclude that SPIONs have an overall good soldering profile. When compared to conventional laser tissue soldering using an optical dye as energy transmitter, no direct assumption can be drawn from this study except that the tensile forces achieved with electromagnetic SPIONs soldering are comparatively higher than the usually reported laser optical tissue soldering forces using the same irradiation area [11]. Conventional suturing with microsurgical technique has shown values to be in the same range as the tissue soldering found in this series, therefore suggesting that this new electromagnetic tissue soldering technique is promising for tissue adaptation at least in the limits of microsurgery. The aim of this study was not to prove any superiority of electromagnetic heating over conventional suturing, but the feasibility 
of electromagnetic tissue soldering and the potential to use this technique. Tensile strength in sutureless tissue fusion whether by using an electromagnetic or laser energy source is certainly proportional to the area of fused tissue. Yet it is only one variable that has to be taken into consideration. Most importantly, it is the quality of the interface that holds supreme attention i.e., the amount of albumin which can be deposed between the tissue pieces. We have shown that by using a porous polymer interface structure, the tensile strength can be significantly increased [20].

\section{Electromagnetic Tissue Properties and Safety Issues}

Conductivity is defined as a measure of a material's ability to conduct an electric current and is dependent on the applied frequency and the tissue exposed to the electric field. At frequencies higher than $1 \mathrm{GHz}$, conductivity increases steeply [21]. The conductivity is expected to be between 0.1 and $1 \mathrm{~S} / \mathrm{m}$ at the applied frequency of $1.8 \mathrm{MHz}$ with the double vessel layers possessing a thickness between 0.5 to 1 $\mathrm{mm}$ [22]. The energy loss in the tissue over this segment is thus negligible in a local applicable induction system.

The International Electrotechnical Commission (IEC)guidelines recommend not to expose the whole body to more than $4 \mathrm{~W} / \mathrm{kg}$ in a high frequency electromagnetic field [23]. The generator used in this study did not surpass the limits of whole body irradiation of $4 \mathrm{~W} / \mathrm{kg}$ as it was used only locally.

A further requirement for clinical application is the issue of biocompatibility. From SPIONs, it is reported to be eliminated through macrophages eliminating system [24]. The exact pathway of the SPIONS after in vivo use can be traced by MRI and is currently under investigation [25].

\section{CONCLUSION}

Electromagnetic tissue soldering using superparamagnetic iron oxide nanoparticles is possible and produces strong and reproducible tensile strength, comparable to the values obtained with conventional suturing. Improvement in nanoparticle density elevation such as by embedding into a polymer structure and radiofrequency adjustment will optimize further miniaturization process and adaptation to different kinds of tissues.

\section{SUPPORT}

Michael Reinert and Amadé Bregy have been supported by the Swiss National Foundation (Grant No. 3200B0107611). Benedikt Steitz has been supported by the Competence Centre of Materials Science of the Swiss Federal Institute of Technology, Education and Research Unit "Surface, Coating and Particle Engineering", Project PAPAMOD.

\section{ACKNOWLEDGMENTS:}

Peter Bienwald, Siegrist und Partner, Matzingen, Switzerland is thanked for his technical advices concerning the induction devices and for providing support in his laboratory.

We thank Daniel Soltermann, Thörigen, Switzerland providing the rabbit abdominal aortic arteries.

The authors thank R. Nyffenegger and A. Friedrich, Institute of Applied Physics, University of Bern, for technical assistance.

\section{REFERENCES}

[1] Quayle SS, Ames CD, Lieber D, Yan Y, Landman J. Comparison of optical resolution with digital and standard fiberoptic cystoscopes in an in vitro model. Urology 2005; 66(3): 489-93.

[2] Constantinescu MA, Alfieri A, Mihalache G, et al. Effect of laser soldering irradiation on covalent bonds of pure collagen. Lasers Med Sci 2007; 22(1): 10-4.

[3] Ott B, Constantinescu MA, Erni D, Banic A, Schaffner T, Frenz M. Intraluminal laser light source and external solder: in vivo evaluation of a new technique for microvascular anastomosis. Lasers Surg Med 2004; 35(4): 312-6.

[4] McNally KM, Sorg BS, Chan EK, Welch AJ, Dawes JM, Owen ER. Optimal parameters for laser tissue soldering. Part I: tensile strength and scanning electron microscopy analysis. Lasers Surg Med 1999; 24(5): 319-31.

[5] Lauto A, Foster LJ, Ferris L, Avolio A, Zwaneveld N, PooleWarren LA. Albumin-genipin solder for laser tissue repair. Lasers Surg Med 2004; 35(2): 140-5.

[6] Pohl D, Bass LS, Stewart R, Chiu DT. Effect of optical temperature feedback control on patency in laser-soldered microvascular anastomosis. J Reconstr Microsurg 1998; 14(1): 23-9; discussion 9-30.

[7] Hergt R, Andra W, d'Ambly C, et al. Physical Limitis of Hypothermia Using Magnetic Fine Particles. IEEE Trans Magn 1998; 34(5): 3745.

[8] Bregy A, Alfieri A, Demertzis S, et al. Automated end-to-side Anastomosis to the Middle Cerebral Artery: a Feasibility Study. Journal of Neurosurgery. 2008 in Press March 2008.

[9] Kroez M, Lang W, Dickneite G. Wound healing and degradation of the fibrin sealant Beriplast $P$ following partial liver resection in rabbits. Wound Repair Regen 2005; 13(3): 318-23.

[10] Ellman PI, Brett Reece T, Maxey TS, et al. Evaluation of an absorbable cyanoacrylate adhesive as a suture line sealant. J Surg Res 2005; 125(2): 161-7.

[11] Alfieri A, Bregy A, Constantinescu MA, et al. Tight Contact Technique during Side to Side Laser Tissue Soldering of Rabbit Aortas improves Tensile Strength. Acta Neurochir Supp 2007; in press.

[12] Hambleton J, Shakespeare PG. Thermal damage to skin collagen. Burns 1991; 17(3): 209-12.

[13] Sun Y, Chen WL, Lin SJ, et al. Investigating mechanisms of collagen thermal denaturation by high resolution second-harmonic generation imaging. Biophys J 2006; 91(7): 2620-5.

[14] McNally KM, Sorg BS, Welch AJ, Dawes JM, Owen ER. Photothermal effects of laser tissue soldering. Phys Med Biol 1999; 44(4): 983-1002; discussion 2 pages follow.

[15] Bass LS, Moazami N, Pocsidio J, Oz MC, LoGerfo P, Treat MR. Changes in type I collagen following laser welding. Lasers Surg Med 1992; 12(5): 500-5.

[16] Schober R, Ulrich F, Sander T, Durselen H, Hessel S. Laserinduced alteration of collagen substructure allows microsurgical tissue welding. Science 1986; 232(4756): 1421-2.

[17] Despa F, Orgill DP, Neuwalder J, Lee RC. The relative thermal stability of tissue macromolecules and cellular structure in burn injury. Burns 2005; 31(5): 568-77.

[18] Hilger I, Fruhauf K, Andra W, Hiergeist R, Hergt R, Kaiser WA. Heating potential of iron oxides for therapeutic purposes in interventional radiology. Acad Radiol 2002; 9(2): 198-202.

[19] Ma M, Wu Z, Zhou J, Sun Y, Zhang Y, Gu N. Size dependence of specific power absorption of $\mathrm{Fe} 3 \mathrm{O} 4$ particles in AC magnetic field. Journal of Magnetism and Magentic Materials 2004; 268(1): 33-9.

[20] Bregy A, Steitz B, Petri-Fink A, et al. The use of polycaprolcatone (PCL) and poly-vinyl-alcohol (PVA) in tissue soldering. Meeting Abstract: Tag der klinischen Forschung, University of Bern 2007 Nov. 2007.

[21] Gabriel C, Gabriel S, Corthout E. The dielectric properties of biological tissues: I. Literature survey. Phys Med Biol 1996; 41(11): 2231-49.

[22] Schneiderman G, Pritchard WF, Ramirez CA, Colton CK, Smith KA, Stemerman MB. Rabbit aortic medial thickness under relaxed 
and specified simulated in vivo conditions. Am J Physiol 1983; 245(4): H623-7.

[23] CENELEC. Medical electrical equipment: IEC 60601-2-33: 2002. BSI 2002.

[24] Neuberger T, Schopf B, Hofmann H, Hofmann M, von Rechenberg B. Superparamagnetic nanoparticles for biomedical applications:
Possibilities and limitations of a new drug delivery system. J Magn Magn Mater 2005; 293(1): 483-96.

[25] Mordasini P, Loennfors-Weitzel T, Bregy A, et al. Sequence optimization at 3 Tesla MRI preliminary to SPION imaging in the context of tissue soldering. Poster Presentation, Swiss Society of Neurosurgery Annual Meeting 2007. 